\title{
THE EFFECT OF LARVAL SELECTION ON ADULT RESISTANCE TO DDT IN TWO STRAINS OF THE MOSQUITO AEDES AEGYPTI (L)
}

\author{
J. P. MARGHAM* and R. J. WOOD \\ Department of Zoology, University of Manchester
}

Received 22.vii.75

\section{SUMMARY}

Evidence is presented which confirms the influence of linkage group II on adult DDT-resistance in one strain of Aedes aegypti (Bangkok-MR) but not in - nother strain (Bangkok-HR).

\section{InTRODUCTION}

LARVAE of Aedes aegypti inherit DDT resistance through the gene $R^{\mathrm{DDT} 1}$ on linkage group II. This is true of all strains investigated. However, when genetic studies are made on adults, a different mode of inheritance appears in different strains. Thus the $\mathrm{T} 8$ strain derives its adult resistance entirely from the gene $R^{\mathrm{DDT} 2}$ on linkage group III (Wood, 1967) as does the Bangkok-HR strain, while resistance in Bangkok-MR comes from both group II and group III (Margham and Wood, 1975). All resistance genes are semi-dominant, giving intermediate resistance characteristics in the $\mathrm{F}_{1}$ (resistant $\times$ susceptible).

Bangkok-MR was derived from Bangkok-HR by outcrossing to a susceptible strain and reselecting with DDT (Margham and Wood, 1974). It is concluded that the penetrance of the two major resistance genes in adults is subject to an influence from the genetic background.

As a follow-up to this work it seemed interesting to observe the effect on adult resistance of prior selection with DDT of larvae of the backcross $\mathrm{F}_{1}$ (resistant $\times$ susceptible) $\times$ susceptible (the procedure being to keep the survivors of larval exposure and retest them as adults). The backcross would carry the $R^{\mathrm{DDT} 1} /+$ and $+/+$ genotypes in equal frequency. Removal of $+/+$ by selection would be expected to increase adult resistance if $R^{\text {DDT1 }}$ is active (penetrant) in the adult (as in Bangkok-MR) but not if $R^{\mathrm{DDT} 1}$ is inactive in the adult (as in Bangkok-HR).

The importance of $R^{\mathrm{DDTl}}$ alone in larval resistance has been shown in other work on the two Bangkok strains (Margham, 1970), where survivors of larval selection gave independent assortment between larval resistance and marker genes on groups I and III. $R^{\mathrm{DDT} 1}$ was shown to be closely linked to a group II marker called spot: $2 \cdot 20 \pm 0.5$ per cent in Bangkok-HR, and $2 \cdot 40 \pm 0 \cdot 7$ per cent in Bangkok-MR.

\section{MAterials AND MEthods}

Four laboratory strains were used:

1. Bangkok-HR, a highly DDT-resistant strain (Margham and Wood, 1975).

* Present address : Biology Department, Liverpool Polytechnic, Byrom Street, Liverpool L3 3AF. 
2. Bangkok-MR, a highly DDT-resistant strain marked on each linkage group (Margham and Wood, 1974).

3. QS, a DDT-susceptible strain.

4. 64, a marked DDT-susceptible strain which had been outcrossed to QS to improve viability.

Each DDT-resistant strain was outcrossed to a DDT-susceptible stock: Bangkok-HR to strain 64, Bangkok-MR to strain QS. The $F_{1}$ 's were then backcrossed to strain 64 and selection applied to the larval stage at a level sufficient to kill approximately 50 per cent of individuals. The survivors were then reared to the adult stage and females re-tested with 2 per cent DDT when 4-6 days old. Females only were tested because they gave a more uniform response than the males. Larvae were treated with DDT using the procedure recommended by the World Health Organisation (WHO, 1963); adult testing procedures were as outlined by Margham and Wood (1975). Controls, i.e. adults derived from unexposed larvae, were tested for comparison in each case.

\section{REsUlts AND DISGUSSION}

The two series of adult tests gave different results. Adults from selected larvae in the backcross involving Bangkok-MR showed a significantly higher tolerance level $\left(\chi^{2}=5.52 ; \mathrm{P}<0.025\right.$, calculated from the knockdown at 2 hours) compared with adults from unselected larvae of the same backcross (fig. 1). By contrast, adults from selected larvae in the Bangkok-HR back-

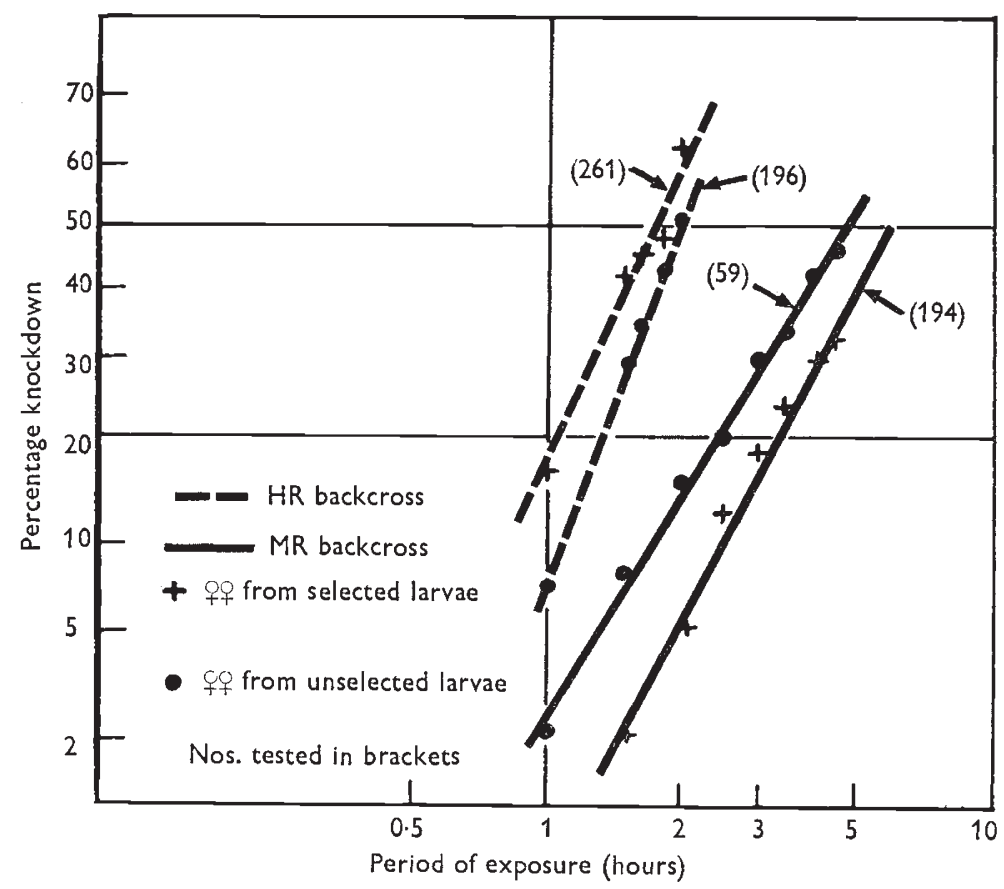

Fig. 1.-Tolerance levels at 2 per cent DDT in female adults derived from (i) DDT-selected and (ii) unselected larvae of backcrosses $F_{1}$ (resistant $\times$ susceptible) $\times$ susceptible using the MR and HR resistant strains. 
cross showed a lower tolerance compared with adults from unselected larvae. This difference was significant $\left(\chi^{2}=5 \cdot 26 ; \mathrm{P}<0 \cdot 025\right)$.

Failure to observe any increase in adult resistance after larval selection in the Bangkok-HR strain indicates (as expected) that the larval resistance gene is playing little part in conferring resistance to the adult. The fact that adult resistance after larval selection was lower, suggests a weakening posttreatment effect of the insecticide.

The significant increase in adult resistance observed in the Bangkok-MR backcross following larval selection reflects the fact that in this strain the larval resistance gene $R^{\mathrm{DDT} 1}$ plays a part in adult tolerance. That the increase after selection was not even more marked may have been the result of a counter-effect of larval selection on adult tolerance as observed in Bangkok-HR. It is of interest that resistance is consistently higher in the backcross involving Bangkok-MR. This is added evidence for the penetrance of $R^{\mathrm{DDT1}}$ enhancing the effect of $R^{\mathrm{DDT} 2}$ at the adult stage.

\section{REFERENGES}

margham, J. P. 1970. Genetical studies on the yellow fever mosquito Aedes aegypti. Ph.D. thesis, Manchester University.

MARGHAM, J. P., AND wOOD, R. J. 1974. The production of a DDT-resistant strain of Aedes aegypti (L.) marked on all three linkage groups. Can. 7. Genet. Cytol., 16, 883-888.

MARGHAM, J. P., AND WOOD, R. J. 1975. A genetical study of DDT resistance in the mosquito Aedes aegypti (L.). Heredity, 34, 53-59.

WHO. 1963. Insecticide resistance and vector control: 13th report of the Expert Committee on Insecticides. Tech. Rep. Ser. Wld Hlth Org., 265, 41-56.

wood, R. J. 1967. A comparative genetical study on DDT resistance in adults and larvae of the mosquito Aedes aegypti. Genet. Res., 10, 219-228. 